Fabio Bucciol, Gertraud Scholz, Hans Jürgen Scholz and Giancarlo Cravotto*

\title{
Microwave-assisted protocol for squalene isolation and conversion from oil-deodoriser distillates
}

https://doi.org/10.1515/gps-2019-0056

Received March 02, 2019; accepted July 02, 2019.

\begin{abstract}
Aiming to design a green and efficient protocol for squalane production from low-cost biomasses, a practical and scalable procedure for squalene extraction and hydrogenation to squalane is presented herein. The oil-deodoriser distillates that are produced by the vegetal-oil production chain are a renewable and cheap source of squalene. We were able to isolate an enriched fraction containing $89.0 \%$ of pure squalene (yield $55.4 \%$ ) from a matrix containing about $2 \%$ squalene. Efficient microwave-assisted esterification under heterogeneous catalysis enabled the separation of fatty-acid methyl esters (FAME) via vacuum distillation. The residue was purified by flash-chromatography on a C-18 silica column using $\mathrm{MeOH} / \mathrm{H}_{2} \mathrm{O} / 2$-propanol as the mobile phase. Finally, squalene was hydrogenated to the more stable squalane in a pressure-resistant microwave reactor. The reaction was performed over a $\mathrm{Pd} / \mathrm{C}$ catalyst in $\mathrm{EtOH}$, and even in solvent-free conditions, and was optimised using commercial squalene ( 5 bar of $\mathrm{H}_{2}$ at $100^{\circ} \mathrm{C}$ for $1 \mathrm{~h}$ ).
\end{abstract}

Keywords: deodoriser distillates; squalene; microwaves; esterification; hydrogenation

\section{Introduction}

Oil-deodoriser distillates (ODD) are residual materials from the refining process of vegetal oils and mostly contain free fatty acids (FFA), but also bioactive compounds, such as sterols, terpenoids and vitamins. Squalene (a C 30 terpenoid) is one of the most valuable target compounds to be isolated using the biorefinery

\footnotetext{
* Corresponding author: Giancarlo Cravotto, Dipartimento di Scienza e Tecnologia del Farmaco, University of Turin, via P. Giuria 9, 10125 Turin, Italy; Centre of Bioanalytical Research and Molecular Design, Sechenov First Moscow State Medical University, 8 Trubetskaya ul, Moscow, Russia; e-mail: giancarlo.cravotto@unito.it

Fabio Bucciol, Dipartimento di Scienza e Tecnologia del Farmaco, University of Turin, via P. Giuria 9, 10125 Turin, Italy

Gertraud Scholz and Hans Jürgen Scholz, IP\&PM GmbH, In den Mühlgärten 58, 63755 Alzenau, Germany
}

strategy, which aims to valorise all the co-products and by-products of oil production. Squalene is involved in the bio-synthesis of cholesterol [1], and is widely used in personal care products as fully hydrogenated squalane. The latter is known for its moisturising and emollient properties, although the use is limited due to the relatively high processing cost of recovery and hydrogenation. The global market size for squalene was valued at $\$ 110$ million in 2015 and is expected to grow at an annual rate of $10.1 \%$, to reach $\$ 214$ million by 2022 [2] on account of its nutritional and health benefits, which include white blood-cell rejuvenation, immunesystem stimulation, anti-carcinogenic and antioxidant properties. Squalene is seeing increasing use as a cleansing and moisturising compound in personal care and cosmetic products, including creams, lotions, lipsticks, bath oils, sunscreens, hair conditioners and foundations (Figure 1), and it is thought that this will propel industry growth [3].

Besides the anti-oxidant properties of squalene (radical scavenger), other activities have been documented: antibiotic, anticoagulant (reducing thrombocyte aggregation, disintegrate blood clots) and immunostimulant (improving resistance, supporting development and activity of phagocytes and lymphocytes) [4]. The expected continued growth of the squalene market raises the question of supply. Squalene is still, in part, extracted from shark-liver oil [5] and of course from vegetable oil. The former results in intensive shark fishing and progressively leads to extinction dangers, because of the animal's long reproductive cycle and slow growth. Therefore, fishing quotas for these shark species have been drastically reduced in Europe [6].

Recent years have seen new advances in extraction technologies and processing that make use of nonconventional energy sources, such as dielectric heating [7], to address the requirements of green extraction principles [8]. Greener methods have to use renewable resources, such as vegetable oils, seeds or related by-products [9]. Vegetable ODD is a suitable and cheap source with which to achieve this aim. Even so, extraction from vegetal sources can involve costly processes such as supercritical $\mathrm{CO}_{2}$ extraction [10,11] and time-consuming 


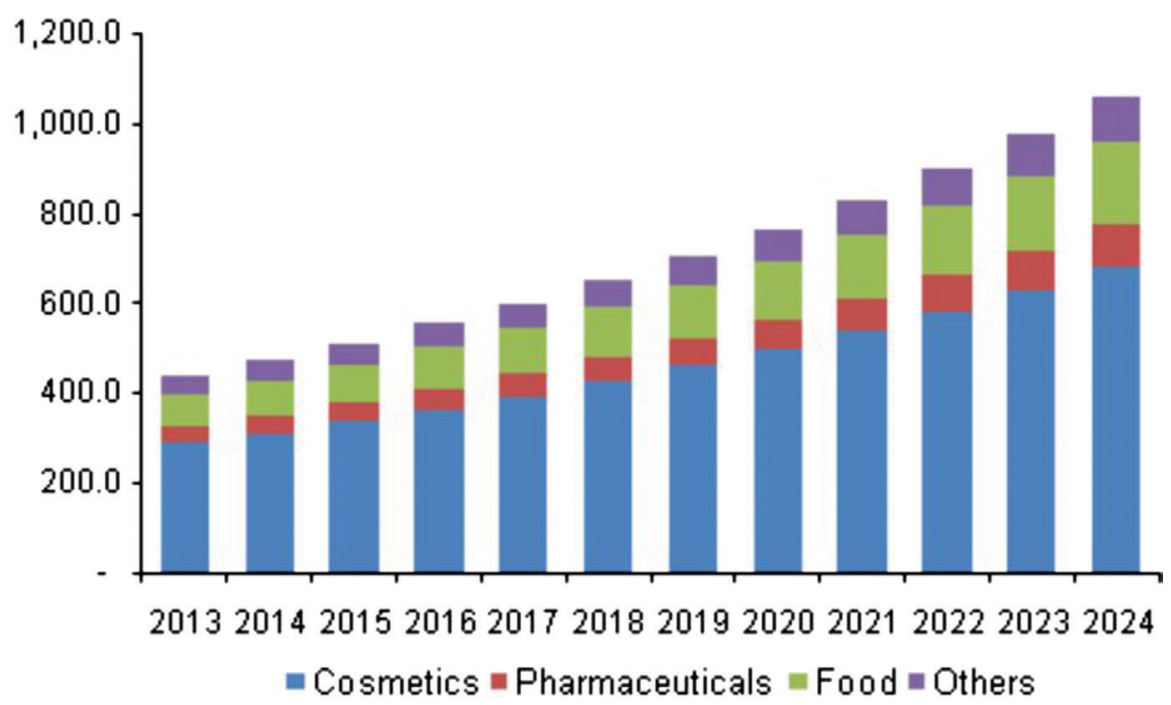

Figure 1: US squalene market by application in tons (from https://www.grandviewresearch.com/industry-analysis/squalene-market).

Soxhlet extraction [12], which also involves a large amount of organic solvents. Angelis et al. have recently reported a centrifugal partition methodology for squalene separation from olive ODD with a final purity of $85 \%$ and $76.3 \%$ yield [13]. Though promising, this approach involves complex technology and is hardly scalable to standardised industrial plants.

The squalene hydrogenation reaction is usually carried out at high temperatures (reaching $200^{\circ} \mathrm{C}$ ) and $\mathrm{H}_{2}$ pressure (4-30 bar) using Ni-based catalysts [14]. Kaliaguine et al. have reported a novel Pd-based catalyst for squalene reduction under milder conditions $\left(180^{\circ} \mathrm{C}\right.$ and 3 bar $\left.\mathrm{H}_{2}\right)$, although it required $7 \mathrm{~h}$ of reaction time [15]. In our work, we propose a complete procedure for squalene isolation and reduction using efficient greener protocols with microwaves (MW) as an enabling technology. MW irradiation is known for its higher energetic efficiency, as compared to conventional heating, and for much shorter reaction times. The peculiar volumetric and selective heating provided by MW requires reactor walls that are transparent to MW, creating an inverse thermal gradient where the reaction mixture is hotter than the external container. The improved heat transfer makes it faster and inhibits secondary reactions on the reactor surfaces $[16,17]$. Acid catalysed MW-assisted esterification is strongly accelerated by MW and has a positive impact on the quality of the isolated squalene [18]. Our experience on MW-assisted esterification comparing dielectric and conductive heating is dating back to the first decade of the century [19]. So far no other technology is fostering this mechanism [20] such as MW with relevant applications in MW-assisted transesterification for biodiesel production where an energy saving of about $50 \%$ was calculated [21]. Impressive effect on reaction rate was observed on selective semi-hydrogenations both in batch [22] and in flow [23].

\section{Materials and methods}

Soybean and mixed-vegetable ODD were used as sources of squalene; these industrial by-products are rich in FFA and were first subjected to esterification with $\mathrm{MeOH}$ to give the corresponding fatty-acid methyl esters (FAME). The first purification step entails FAME removal by vacuum distillation. The residue was further purified by preparative flash-chromatography. The squalene-enriched fraction was then hydrogenated under microwave irradiation using $\mathrm{Pd} / \mathrm{C} 10 \mathrm{wt} \%$ as a catalyst.

Soybeans and mixed vegetables ODD were provided by Cereal Docks. For the esterification, methanol ( $\geq 99.9 \%)$ and $p$-toluenesulfonic acid ( $\geq 98.5 \%)$ were purchased from Sigma-Aldrich ${ }^{\circledast}$, acid zeolites were purchased from Alfa Aesar and acid silicas from SiliCycle Inc. Chromatographic separation was performed using CombiFlash ${ }^{\circledR}$ rf 200 by Teledine ISCO and RediSep ${ }^{\circledR}$ inverse phase C-18 silica columns. Isopropyl alcohol $(\geq 99.7 \%)$ was purchased from Sigma-Aldrich ${ }^{\circledast}$. The MW reactor used for esterification and the hydrogenation step was a SynthWAVE (Milestone Srl, Bergamo, IT). Pd/C (10 wt\%) was purchased from SigmaAldrich $^{\circledast}$. Commercial squalene $(\geq 98 \%)$ was purchased from Sigma-Aldrich ${ }^{\circledR}$. 
NMR analyses were performed on a Jeol $600 \mathrm{MHz}$ in $\mathrm{CDCl}_{3}(99.80 \%)$ from Eurisotop. GC-MS analyses were performed on an Agilent 6850 equipped with an Agilent 5973 quadrupole detector and a MEGA-5 MS low polarity column.

\subsection{ODD characterisation}

The actual FFA content was estimated via basic titration. In this step, $10 \mathrm{~g}$ of ODD were dissolved in a 3:1 solution of diethylether and ethanol and mixed under magnetic stirring. $\mathrm{NaOH} 0.1 \mathrm{~N}$ was added dropwise using phenolphthalein as the $\mathrm{pH}$ indicator. Soy ODD (SOY) showed an acid content of $2.3 \mathrm{mmol} / \mathrm{g}$, while mixed-vegetable ODD (MIX) gave an acid content of $3.0 \mathrm{mmol} / \mathrm{g}$. The $600 \mathrm{MHz}{ }^{1} \mathrm{H}$ and ${ }^{13} \mathrm{C}$ NMR spectra in $\mathrm{CDCl}_{3}$ of both the ODD were recorded for the comparison of the treated samples and also after the esterification step. The esterified matrix was then analysed by GC-MS. This was primarily used to estimate the squalene content, which was found to be around $1.6 \%$ of the total compounds for MIX and 2.1\% for SOY (Table 1).

\subsection{Esterification process}

The esterification step was performed using a range of catalysts. $p$-Toluenesulfonic acid (PTSA) is a widely known homogeneous acid catalyst [24,25], and was used in our experiments as a reference catalyst. We investigated the catalytic properties of five different heterogeneous catalysts: three zeolites and two acidic silicas (Table 2).

The reactions were performed in a MW reactor under $\mathrm{N}_{2}$ pressure (7 bar). For reactions with heterogeneous catalysts, the reaction mixtures were filtered on paper and then the residual $\mathrm{MeOH}$ was evaporated under vacuum. When PTSA was used, the catalyst was recovered via solvent extraction; the samples were dissolved in chloroform and then washed with an excess of water three times. The organic fraction was then collected, and the remaining water was adsorbed onto anhydrous $\mathrm{Na}_{2} \mathrm{SO}_{4}$. The sample was then filtered and the solvent evaporated under vacuum.

\subsection{Separation process}

FAME removal was achieved via vacuum distillation at high temperature using a kugelrohr. For both ODD types, approximately $2 \mathrm{~g}$ of material could be treated at a time;
Table 1: Percentage composition of MIX and SOY.

\begin{tabular}{llr}
\hline Substrate & Component & Content \% \\
\hline & Palmitic acid m.e. & 5.4 \\
& Kaur-15-ene & 0.3 \\
& Linolenic acid m.e. & 9.9 \\
\hline & Oleic acid m.e. & 78.3 \\
& Stearic acid m.e. & 3.3 \\
13-Eicosenoic acid m.e. & 0.1 \\
& Eicosanoic acid m.e. & 0.4 \\
& Docosanoic acid m.e. & 0.7 \\
Squalene & 1.6 \\
\hline & Neophytadiene & 0.4 \\
& Palmitic acid m.e. & 12.4 \\
9,12-Octadecadienoic acid m.e. & 35.7 \\
& Oleic acid m.e. & 20.6 \\
& Stearic acid m.e. & 3.6 \\
& Linoleic acid m.e. & 1.1 \\
& Heptadecanoic acid m.e. & 0.2 \\
Squalene & 2.1 \\
& $\gamma$-Tocopherol & 7.8 \\
& $\alpha$-Tocopherol & 1.4 \\
& Campesterol & 3.4 \\
& Stigmasterol & 3.7 \\
& $\gamma$-Sitosterol & 7.6 \\
\hline & &
\end{tabular}

Table 2: Characteristics of acidic catalysts.

\begin{tabular}{lrrrr}
\hline Catalyst & $\begin{array}{r}\mathrm{SiO}_{2}: \mathrm{Al}_{2} \mathbf{O}_{3} \\
(\mathrm{~mol}: \mathrm{mol})\end{array}$ & $\begin{array}{r}\text { Acid sites } \\
(\mathrm{meq}: \mathrm{g})\end{array}$ & $\begin{array}{r}\text { Surface area } \\
\left(\mathrm{m}^{2} / \mathbf{g}\right)\end{array}$ & $\begin{array}{r}\text { Max T } \\
\left({ }^{\circ} \mathrm{C}\right)\end{array}$ \\
\hline$p$-Toluenesulfonic acid & - & $5.8: 1$ & - & - \\
Zeolite HY 30 & $30: 1$ & $0.03: 1$ & 780 & $>200$ \\
Zeolite HY 5.1 & $5.1: 1$ & $0.14: 1$ & 730 & $>200$ \\
Zeolite $\beta$ & $360: 1$ & - & 620 & $>200$ \\
SiO - Propylsulfonic & - & $0.80: 1$ & $480-550$ & 120 \\
$\quad$ acid & & & & \\
$\mathrm{SiO}_{2}$ - Tosic acid & - & $0.84: 1$ & $480-550$ & 120 \\
\hline
\end{tabular}

once the vacuum was applied the temperature was kept at $200^{\circ} \mathrm{C}$ for $1 \mathrm{~h}$. The distillation residue still contained a small percentage of FAME, but was strongly enriched in high-boiling compounds, such as squalene.

The final separation was performed using flashchromatography. The columns were packed with reversephase C-18 silica column, and the mobile phase used was a mix of $\mathrm{MeOH}$ containing $2 \%$ water (solvent $\mathrm{A}$ ) and 2-propanol (solvent $B$ ) in changing proportions, according to the work of X. Liu et al. [26]. The separation was controlled by measuring UV-Vis absorbance at $254 \mathrm{~nm}$ and $214 \mathrm{~nm}$. Preliminary experiments to find the best gradient were conducted on a 26 g RediSep column (max 520 mg of loading), then we moved to a $86 \mathrm{~g}$ column (max $1.7 \mathrm{~g}$ loading) to scale up the process and obtain more material 
for hydrogenation. Prior to chromatography, samples were dissolved in $\mathrm{CH}_{2} \mathrm{Cl}_{2}$ and adsorbed on normal phase silica to be placed in a pre-column cartridge.

This procedure gives four different fractions (I, II, III and IV) that were then concentrated under vacuum evaporation, weighed and analysed by GC-MS. The first two were rich in FAME, with I being the most rich in saturated FAME and II in unsaturated. Fraction III also contains FAME but has a high concentration of vitamins and sterols. Fraction IV is the squalene rich fraction.

\subsection{Hydrogenation process}

The hydrogenation of squalene was carried out in a MW reactor under $\mathrm{H}_{2}$ pressure using $\mathrm{Pd} / \mathrm{C} 10 \mathrm{wt} \%$ as the catalyst. The reagent and catalyst were placed in a $20 \mathrm{~mL}$ glass vial under magnetic stirring. The reaction chamber was a $1 \mathrm{~L}$ PTFE cavity filled with $200 \mathrm{~mL}$ of water $(20 \mathrm{wt} \%$ $\mathrm{NaCl}$ ), which absorbs the radiation excess. Even though the water bath also heats up, the thermal energy for the reaction comes from the inside of the vial (especially from the catalyst), through the inverse thermal gradient typical of MW radiation.

Experimental conditions were optimised using commercial squalene. The reaction was also carried on both with and without the use of ethanol as a solvent. The literature has shown that the reaction occurs in neat conditions, but EtOH improves the kinetics by easing hydrogen dissolution into the liquid phase [27]. After the reaction, the samples were filtered on paper and HPLC filters, and then both analysed using GC-MS and ${ }^{1} \mathrm{H}-\mathrm{NMR}$ to measure conversion and selectivity.

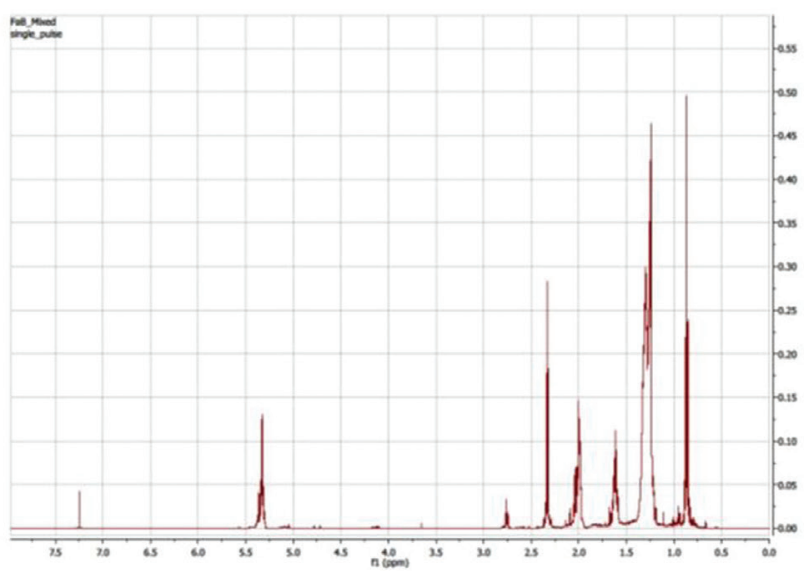

\section{Results and discussion}

\subsection{Esterification of FFA}

After preliminary esterification tests under harsh conditions and using long reaction times with PTSA to ensure the complete conversion of FFA to FAME, milder conditions were tested. GC-MS and ${ }^{1} \mathrm{H}-\mathrm{NMR}$ analysis were used to confirm the full conversion (Figure 2).

The complete conversion of MIX and SOY was achieved with PTSA in $1 \mathrm{~h}$ at $100^{\circ} \mathrm{C}$, using $5.3 \mathrm{mg}$ of catalyst and $1.4 \mathrm{~mL}$ of $\mathrm{MeOH}$ for every millimole of FFA. The methyl peak is clearly visible in the NMR spectra and residual FFA, if present, was under the detection limit of the GC-MS. Doubling the reaction time or increasing the PTSA quantity resulted in no differences in the analyses. We then proceed with the experiments using the different heterogeneous catalysts. The optimised reaction conditions for every catalyst are listed in Table 3.

It is not surprising that PTSA is the most active, since it combines good acidity with optimal contact

Table 3: Reaction conditions with the various catalysts.

\begin{tabular}{lrrrr}
\hline Catalyst & Cat:FFA $^{\mathrm{a}}$ & MeOH:FFA $^{\mathrm{b}}$ & $\begin{array}{r}\text { Time } \\
\text { (hours) }\end{array}$ & $\begin{array}{r}\mathbf{T} \\
\left({ }^{\circ} \mathrm{C}\right)\end{array}$ \\
\hline PTSA & $2.5: 1$ & $0.16: 1$ & 1 & 100 \\
Zeolite HY 30 & $100: 1$ & $1.3: 1$ & 2 & 100 \\
Zeolite $\beta$ & $100: 1$ & $1.3: 1$ & 2 & 100 \\
$\mathrm{SiO}_{2}$ - Propylsulfonic acid & $56: 1$ & $0.16: 1$ & 2 & 100 \\
$\mathrm{SiO}_{2}$ - Tosic acid & $56: 1$ & $0.16: 1$ & 1 & 100 \\
\hline
\end{tabular}

Reaction conducted under $\mathrm{N}_{2}$ pressure (7 bar), average $\mathrm{MW}$ power $350 \mathrm{~W}$. Ratios calculated as $\mathrm{mg}: \mathrm{mmol}$ for $\mathbf{a}$ and $\mathrm{mL}: \mathrm{mmol}$ for $\mathbf{b}$.

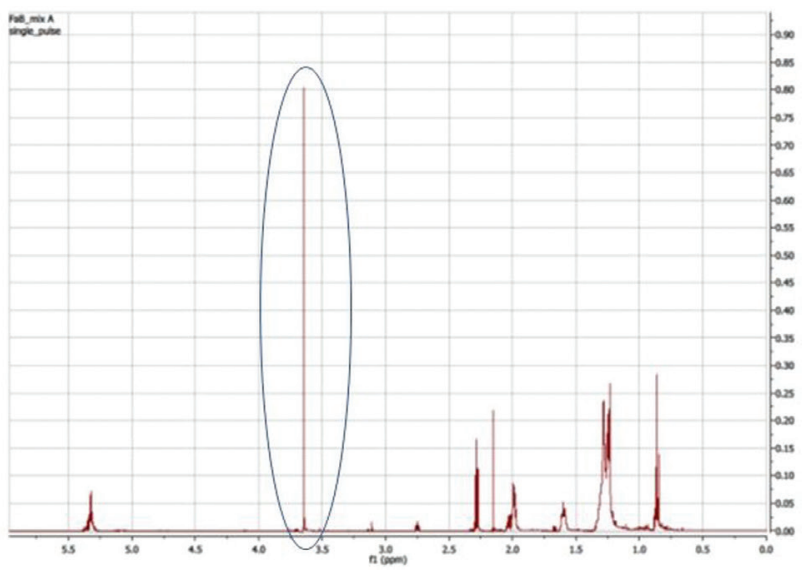

Figure 2: ${ }^{1} \mathrm{H}$ NMR of MIX pre and post esterification. The methyl ester peak is highlighted. 
with the liquid reagents. For the zeolites, zeolite HY 5.1 is not listed as it could not reach complete conversion of the FFA even under the harsher conditions. Complete esterification was achieved both with HY 30 and $\beta$. A possible explanation for this is that, even if zeolite HY 5.1 is the most acidic, its polar cavities cannot properly host the reagents. This is also in accordance with the good results produced by zeolite $\beta$, which is less acidic, but has highly hydrophobic cavities. The results of the silicas are directly linked to their acidity. Both contain more acidic sites than the zeolites and so can be used in lower quantities. Even though the homogeneous catalyst is still the best, these trials show that complete esterification of ODD can be achieved under mild conditions using the most suitable heterogeneous catalyst.

\subsection{Vacuum distillation}

With the subsequent vacuum distillation step at $200^{\circ} \mathrm{C}$ for $1 \mathrm{~h}$, it is possible to recover about $30 \mathrm{mg}$ of FAME for every gram of sample, that is a $3 \mathrm{wt} \%$ yield. This was tested both on SOY and MIX ODDs, in the presence of PTSA or heterogeneous catalysts. GC-MS analyses showed no trace of squalene in the distillates, meaning that it was instead concentrated in the residue and that the process is selective. In our case, it was not possible to test lower temperatures and, after $1 \mathrm{~h}$, the sample started to degrade. Given these practical limitations, this step only functions as a proof of concept. However, this step is not necessarily needed for squalene recovery as the separation from FAME is good in the chromatographic column and skipping it entirely did not influence the final yield of squalene.

\subsection{Squalene recovery and hydrogenation to squalane}

As previously mentioned, preliminary separation tests were performed on a small scale using $26 \mathrm{~g}$ C-18 silica column starting from $200 \mathrm{mg}$ of sample. A typical chromatogram is shown in Figure 3.

At the beginning, the polar mobile phase easily elutes most of the FAME in fractions I and II. The quantity of B was then increased to enhance the mobility of the other, larger molecules. Squalene is eluted in the last fraction, reaching a purity of $46.0 \%$ for MIX and $42.6 \%$ for SOY. The overall composition of each fraction is listed in Table 4.

Given the feasibility of the method, we set up largescale experiments with an $86 \mathrm{~g} \mathrm{C}-18$ silica column. The column change required an adjustment of the gradient, increasing the B percentage to properly elute the squalene fraction. Under these conditions, fraction IV achieved a squalene content of $87.4 \%$ for MIX and $89.0 \%$ for SOY. The yield for the latter was calculated to be $55.4 \%$. SOY IV, the purest sample obtained, only contained tetracosanoic acid methyl ester as the major impurity, while other sterols and saturated hydrocarbons were present in traces below $1 \%$ each (Figure 4).

The hydrogenation reaction was first optimised using commercial squalene. As shown in the table below, adding ethanol as a solvent allows milder conditions to be used, although it is still possible to reduce neat squalene. Although conversion was complete in some

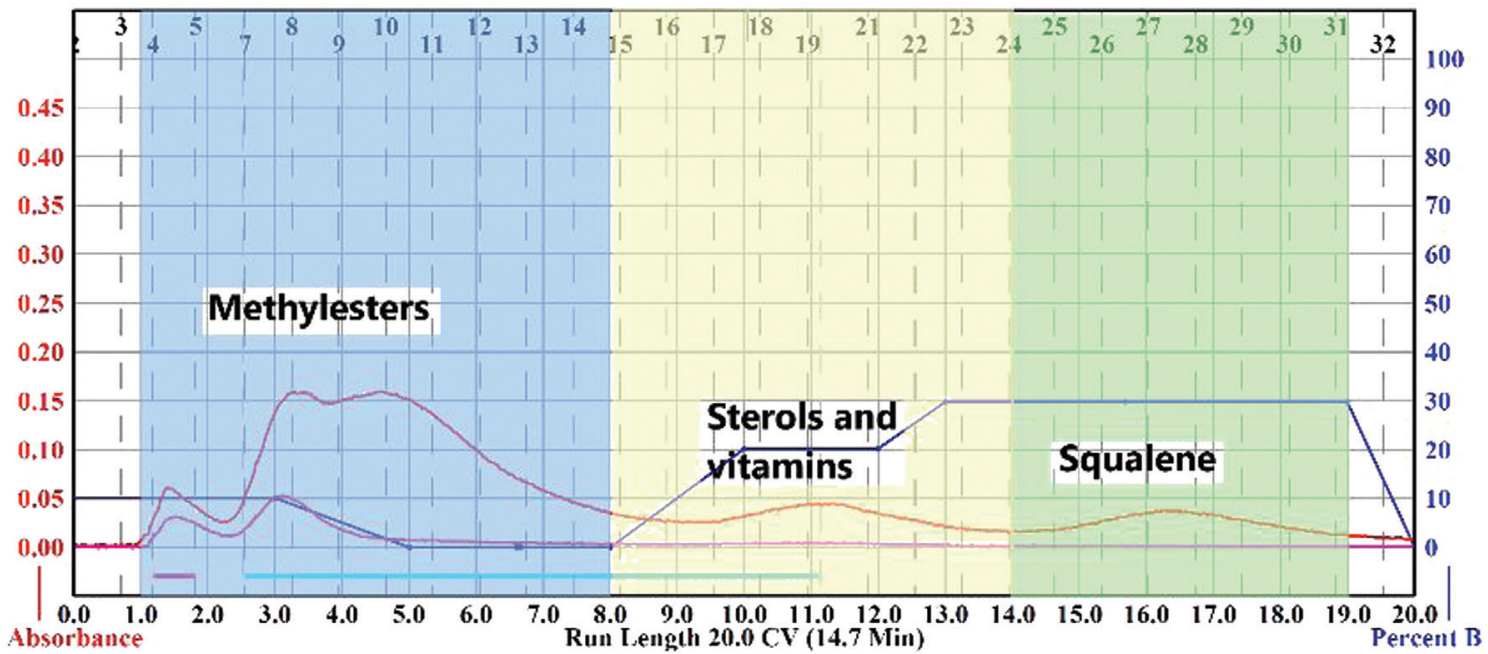

Figure 3: Chromatogram with a 26 g C-18 silica column. 
Table 4: Percentage composition of the squalene-enriched fractions.

\begin{tabular}{|c|c|c|c|c|c|c|c|}
\hline \multirow{2}{*}{$\frac{\text { Substrate }}{\mathrm{MIX}}$} & \multirow{2}{*}{$\frac{\text { Fraction }}{\text { IV }}$} & \multicolumn{6}{|c|}{ Major components } \\
\hline & & $\begin{array}{l}\text { Squalene } \\
(46.0 \%)\end{array}$ & $\begin{array}{l}\text { Docosanoic acid } \\
\text { m.e. }(18.7 \%)\end{array}$ & $\begin{array}{l}\text { 9,12-Octadecadienoic acid } \\
\text { + Oleic acid m.e. (10.3\%) }\end{array}$ & $\begin{array}{l}\text { Tetracosanoic acid } \\
\text { m.e. }(9.0 \%)\end{array}$ & $\begin{array}{ll}\text { Kaur-15- } & Y \text {-Sitosterol } \\
\text { ene }(6.9 \%) & (3.0 \%)\end{array}$ & $\begin{array}{l}\text { Tricosanoic acid } \\
\text { m.e. }(2.5 \%)\end{array}$ \\
\hline SOY & IV & $\begin{array}{l}\text { Squalene } \\
(42.6 \%)\end{array}$ & $\begin{array}{l}\text { y-Sitosterol } \\
(30.0 \%)\end{array}$ & Stigmasterol (12.4\%) & $\begin{array}{l}\text { Campesterol } \\
(10.5 \%)\end{array}$ & Tetracosanoic acid m.e. & $(1.0 \%)$ \\
\hline
\end{tabular}

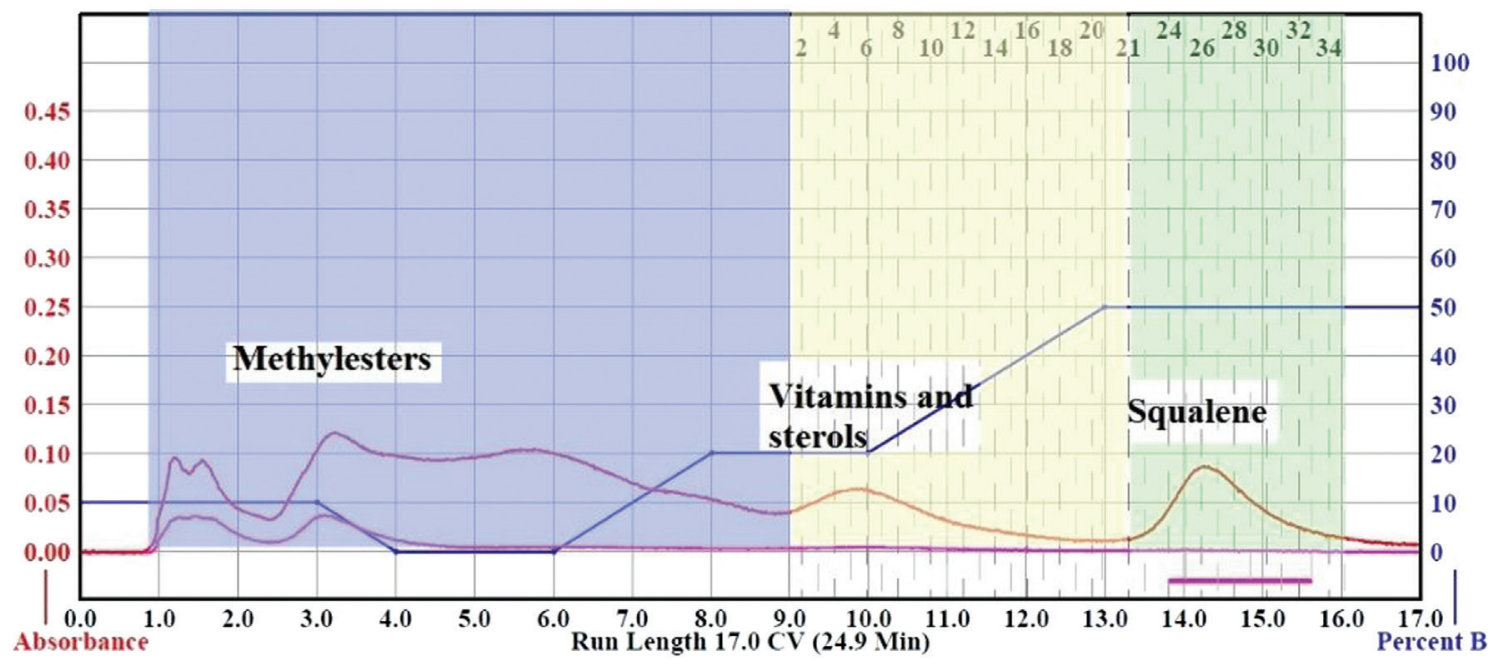

Figure 4: Chromatogram with the $86 \mathrm{~g} \mathrm{C}-18$ silica column.

Table 5: Hydrogenation of commercial squalene.

\begin{tabular}{lrrrrrr}
\hline $\begin{array}{l}\text { Catalyst } \\
(\mathrm{mg})\end{array}$ & $\begin{array}{r}\text { EtOH } \\
(\mathrm{mL})\end{array}$ & $\begin{array}{r}\mathrm{T} \\
\left({ }^{\circ} \mathrm{C}\right)\end{array}$ & $\begin{array}{r}\text { Time } \\
(\text { hours })\end{array}$ & $\begin{array}{r}\mathrm{H}_{2} \\
(\text { bar) }\end{array}$ & $\begin{array}{r}\text { Conversion } \\
(\%)\end{array}$ & $\begin{array}{r}\text { Selectivity } \\
(\%)\end{array}$ \\
\hline 10 & - & 150 & 4 & 10 & 100 & 100 \\
5 & - & 150 & 4 & 10 & 100 & 100 \\
5 & - & 100 & 4 & 10 & 98.3 & 25.0 \\
5 & - & 150 & 4 & 5 & 100 & 15.5 \\
5 & - & 150 & 2 & 10 & 100 & 91.3 \\
5 & - & 150 & 2 & 5 & 100 & 30.9 \\
5 & 2 & 120 & 2 & 5 & 100 & 100 \\
5 & 2 & 100 & 2 & 5 & 100 & 100 \\
5 & 2 & 100 & 1 & 5 & 100 & 98.4 \\
\hline
\end{tabular}

of the trials, selectivity towards squalene was not and the GC-MS chromatogram shows several different peaks around the retention time of squalane. That is proof of incomplete hydrogenation, which gives different compounds with increasing saturation. Results are given in Table 5.

Full conversion was achieved when testing the reaction of squalene from MIX and SOY under the optimised conditions, but selectivity dropped due to the presence of impurities from the separation process (Table 6).
Table 6: Hydrogenation of extracted squalene fraction.

\begin{tabular}{lrrrrrr}
\hline $\begin{array}{l}\text { Catalyst } \\
(\mathrm{mg})\end{array}$ & $\begin{array}{r}\text { EtOH } \\
(\mathrm{mL})\end{array}$ & $\begin{array}{r}\mathrm{T} \\
\left({ }^{\circ} \mathrm{C}\right)\end{array}$ & $\begin{array}{r}\text { Time } \\
(\text { hours })\end{array}$ & $\begin{array}{r}\mathbf{H}_{2} \\
(\text { bar) }\end{array}$ & $\begin{array}{r}\text { Conversion } \\
(\%)\end{array}$ & $\begin{array}{r}\text { Selectivity } \\
(\%)\end{array}$ \\
\hline 5 & 2 & 120 & 2 & 5 & 100 & 31.8 \\
5 & 2 & 100 & 1 & 5 & 100 & 25.0 \\
5 & - & 150 & 4 & 10 & 100 & 29.8 \\
\hline
\end{tabular}

The fact that even such small impurity amounts greatly influence squalane yield is probably linked to catalyst activity rather than the reaction conditions. Indeed, even if some unsaturated molecules take part in the hydrogenation, the $\mathrm{H}_{2}$ pressure is still high enough to theoretically guarantee a complete yield to squalane. It is probable that a screening of other commercial catalysts will lead to better results, especially if we consider that almost complete yields were obtained using the squalene standard. On the base of scaling up to semi-industrial production, feasibility and process sustainability analysis suggested to discard longer reaction times, higher temperatures, and higher $\mathrm{H}_{2}$ pressures. The complete process is depicted in Figure 5. 


\section{From vegetal ODD to squalane}

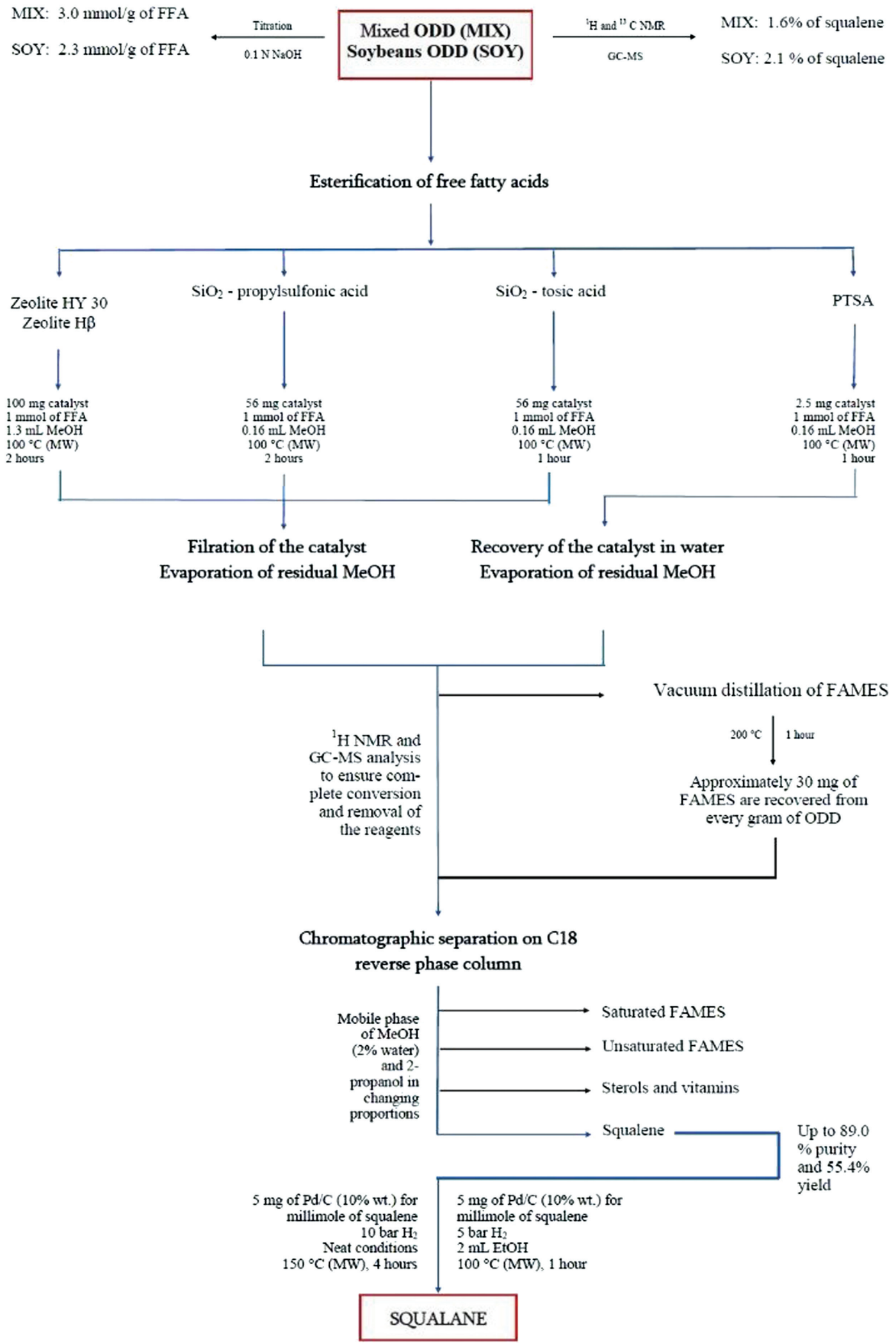

Figure 5: Flow-chart of the whole process. 


\section{Conclusions}

In this work, we have designed a simple and fast protocol for squalene isolation and hydrogenation. MW were successfully used for FFA esterification of the starting material and for final hydrogenation when compared to those actually employed in industries $\left(200^{\circ} \mathrm{C}\right.$ and up to 30 bar of $\mathrm{H}_{2}$ ), giving short reaction times under mild conditions; $10 \mathrm{~g}$ of ODD was esterified in $\mathrm{MeOH}$ in $1 \mathrm{~h}$ at $100^{\circ} \mathrm{C}$. The reaction also occurs under heterogeneous catalysis where the solid material is easily recovered by filtration. After FAME distillation, the residue was fractionated by flash-chromatography reaching $89 \%$ purity $(55.4 \%$ yield $)$. Complete hydrogenation was detected using commercial squalene, both under neat conditions and with EtOH as a solvent. It appears that organic impurities have a strong effect on the catalytic activity, lowering the yield on extracted squalene to $31.8 \%$. Work is in progress to design process scale-up.

\section{References}

[1] Pandit J., Danley D.E., Schulte G.K., Mazzalupo S.M., Pauly T.A., Hayward C.M., et al., Crystal Structure of Human Squalene Synthase a Key Enzyme in Cholesterol Biosynthesis. J. Biol. Chem., 2000, 39, 30610-30617.

[2] Prasad E., Roy A., Squalene Market Size, Trends and Industry Forecast - 2022. 2016, https://www.alliedmarketresearch.com/ squalene-market.

[3] Grand View Research website, https://www.grandviewresearch. com/industry-analysis/squalene-market.

[4] Huang Z.R., Lin Y.K., Fang J.Y., Biological and Pharmacological Activities of Squalene and Related Compounds: Potential Uses in Cosmetic Dermatology. Molecules, 2009, 14, 540-554.

[5] Bloom Association website, http://http://www. bloomassociation.org/en/beauty-and-the-beast-shark-in-ourbeauty-creams/.

[6] Popa O., Băbeanu N.E., Popa I., Niță S., Dinu-Pârvu C.E., Methods for Obtaining and Determination of Squalene from Natural Sources. Biomed. Res. Int., 2015, 2015, 1-16.

[7] Chemat F., Cravotto G., Microwave-assisted extraction for bioactive compounds: Theory and practice. Springer Science, New York, 2013.

[8] Chemat F., Abert-Vian M., Cravotto G., Review: Green Extraction of Natural Products: Concept and Principles. Int. J. Mol. Sci., 2012, 13(7), 8615-8627.

[9] Lozano-Grande M.A., Gorinstein S., Espitia-Rangel E., DávilaOrtiz G., Martínez-Ayala A.L., Plant Sources, Extraction Methods, and Uses of Squalene. Int. J. Agron., 2018, 1-13.
[10] Vázquez L., Torres C.F., Fornari T., Señoráns F.J., Reglero G., Recovery of squalene from vegetable oil sources using countercurrent supercritical carbon dioxide extraction. J. Supercrit. Fluid., 2007, 40, 59-66.

[11] Chang C.J., Chang Y.-F., Lee H.-Z., Lin J.-Q., Yang P.-W., Supercritical carbon dioxide extraction of high-value substances from soybean oil deodorizer distillate. Ind. Eng. Chem. Res., 2000, 39, 4521-4525.

[12] Gunawan S., Kasim N.S., Ju Y.-H., Separation and purification of squalene from soybean oil deodorizer distillate. Sep. Purif. Technol., 2008, 60, 128-135.

[13] Xynos N., Zervos M., Angelis A., Aligiannis N., Skaltsounis A.L., A single-step isolation of squalene from olive oil deodorizer distillates by using centrifugal partition chromatography. Sep. Sci. Technol., 2016, 51, 830-835.

[14] Ciriminna R., Pandarus V., Ois Beíand F., Pagliaro M., Catalytic hydrogenation of Squalene to Squalane. Org. Process Res. Dev., 2014, 18, 1110-1115.

[15] Pandarus V., Ciriminna R., Ois Beíand F., Pagliaro M., Kaliaguine S., Solvent-Free Chemoselective Hydrogenation of Squalene to Squalane. ACS Omega, 2017, 2, 3989-3996.

[16] Cravotto G., Carnaroglio D., Microwave Chemistry (1st ed.). De Gruyter, 2017.

[17] De La Hoz A., Díaz-Ortiz A., Moreno A., Microwaves in organic synthesis. Thermal and non-thermal microwave effects. Chem. Soc. Rev., 2005, 34, 164-178.

[18] Bondioli P., Mariani C., Lanzani A., Fedeli E., Muller A., Squalene recovery from olive oil deodorizer distillates. J. Am. Oil Chem. Soc., 1993, 70, 763-766.

[19] Cravotto G., Boffa L., Turello M., Parenti M., Barge A., Chemical modifications of bile acids under high-intensity ultrasound or microwave irradiation. Steroids, 2005, 70, 77-83.

[20] Caporaso M., Cravotto G., Georgakopoulos S., Heropoulos G., Martina K., Tagliapietra S., Pd/C-catalyzed aerobic oxidative esterification of alcohols and aldehydes: a highly efficient microwave-assisted green protocol. Beilstein J. Org. Chem., 2014, 10, 1454-1461.

[21] Choedkiatsakul I., Ngaosuwan K., Assabumrungrat S., Mantegna S., Cravotto G., Biodiesel production in a novel continuous flow microwave reactor. Renew. Energ., 2015, 83, 25-29.

[22] Zhilin W., Calcio Gaudino E., Rotolo L., Medlock J., Bonrath W., Cravotto G., Efficient partial hydrogenation of 2-butyne-1,4-diol and other alkynes under microwave irradiation. Chem. Eng. Process., 2016, 110, 220-224.

[23] Calcio Gaudino E., Manzoli M., Carnaglio D., Wu Z., Grillo G., Rotolo L., et al., Sonochemical preparation of alumina-spheres loaded with Pd nanoparticles for 2-butyne-1,4-diol semihydrogenation in a continuous flow microwave reactor. RSC Adv., 2018, 13, 7029-7039. 
[24] Brännström S., Finnveden M., Johansson M., Martinelle M., Malmström E., Itaconate based polyesters: Selectivity and performance of esterification catalysts. Eur. Polym. J., 2018, 103, 370-377.

[25] Liu W., Wang F., p-Toluenesulfonic Acid-based Deep Eutectic Solvent as Transesterification Catalyst for Biodiesel Production. J. Oleo Sci., 2018, 14, 1-7.
[26] Yuan C., Ju Y., Jin R., Ren L.L., Liu X., Simultaneous HPLC-DAD analysis of tocopherols, phytosterols, and squalene in vegetable oil deodorizer distillates. Chromatographia, 2014, 78, 273-278.

[27] Pandarus V., Ciriminna R., Kaliaguine S., Béland F., Pagliaro M., Heterogeneously Catalyzed Hydrogenation of Squalene to Squalane under Mild Conditions. ChemCatChem, 2015, 7, 20712076. 